\title{
Impact of moisture on survival of Aedes aegypti eggs and ovicidal activity of Metarhizium anisopliae under laboratory conditions
}

\author{
C Luz/+ ${ }^{+}$MHH Tai, AH Santos, HHG Silva \\ DMIPP, Instituto de Patologia Tropical e Saúde Pública, Universidade Federal de Goiás, 74001-970 Goiânia, GO, Brasil
}

The effect of relative humidity (43\%, 75\%, 86\% and > 98\%) on Aedes aegypti eggs treated with Metarhizium anisopliae or water only was tested for up to a six months exposure at $25^{\circ} \mathrm{C}$. Survival of larvae inside eggs was clearly affected by the lowest humidity (43\%) tested, and eclosion diminished at all humidities after increasing periods of exposure. M. anisopliae showed to have a strong ovicidal activity only at humidity close to saturation. No difference of activity was found between conidia and hyphal bodies tested. This fungus affected larvae inside eggs and has potential as a control agent of this important vector in breeding sites with high moisture.

Key words: entomopathogenic fungi - mosquito - egg - biological control

Aedes aegypti is the principal vector of dengue viruses in tropical and subtropical regions throughout the world. This closely human-associated mosquito uses a great variety of large to small sized breeding sites and occurs year round even in semi-arid regions. Females oviposit mainly above the waterline on damp surfaces, and unhatched larvae have to hold out until immersion of eggs in water will permit eclosion and further development. Populations decline during the dryer and colder season but mosquitoes never disappear completely using subterranean and other breeding sites resulting from watering behavior by local residents (Varejão et al. 2005, Maciel-de-Freitas et al. 2007). Moreover, eggs out of water resist prolonged desiccation during distinct dry seasons, and the surviving larvae contribute to a reestablishment of vector populations at the beginning of the rainy season, thus increasing the risk of dengue epidemics (Sota \& Mogi 1992, Silva \& Silva 1999). Inside eggs, diapausing larvae are exposed to predation and infection by pathogens, particularly fungi that may invade eggs actively through the egg shell or affect larvae with toxic metabolites produced on the egg surface (Russell et al. 2001, Luz et al. 2007). Moisture is a limiting factor for both egg survival and fungal activity but there is still little information about the impact of relative humidity (RH) on the survival of larvae inside eggs or a possible effect of entomopathogenic fungi.

We report here on the impact of $\mathrm{RH}$ on egg survival and an ovicidal activity of $M$. anisopliae under laboratory conditions. This fungal species is pathogenic to larvae and adults of A. aegypti (Scholte et al. 2004, 2007, Silva et al. 2004, 2005), and recent studies indicated

+ Corresponding author: wolf@iptsp.ufg.br

Received 18 September 2007

Accepted 14 March 2008 that it is also effective against eggs of this vector (Luz et al. 2007). The fungal isolate tested here, IP 46, originated from a soil sample collected in 2001 in the Cerrado of Central Brazil and was stored at the IPTSP, UFG, Goiânia, Brazil. Conidia were collected from 15 days old sporulating cultures grown in Petri dishes (100 x $20 \mathrm{~mm}$ ) at $25^{\circ} \mathrm{C}$ and $12 \mathrm{~h}$ photophase on potato-dextrose-agar; hyphal bodies were produced in liquid Sabouraud-dextrose-yeast extract medium (Goettel \& Inglis 1997) for five days on a rotary shaker at $25^{\circ} \mathrm{C}$ and $240 \mathrm{rpm}$.

The population of $A$. aegypti originated from virusfree larvae, collected in 1991 in Goiânia, Brazil. Mosquitoes were reared under laboratory conditions as described by Silva et al. (1998). Eggs were prepared using the method related by Luz et al. (2007), and then topically treated with $50 \mu \mathrm{l}$ water-suspended conidia or hyphal bodies, at $5 \times 10^{6}$ propagules $/ \mathrm{cm}^{2}$ or with water only for the controls and incubated for up to six months at $25^{\circ} \mathrm{C}$ and $43 \%, 75 \%, 86 \%$ or $>98 \% \mathrm{RH}$ regulated in the test chambers with saturated solutions of $\mathrm{K}_{2} \mathrm{CO}_{3}, \mathrm{NaCl}$, $\mathrm{KCl}$ and $\mathrm{K}_{2} \mathrm{SO}_{4}$, respectively (Winston \& Bates 1960). Each month, fungal development on eggs and egg viability were tested. Eggs were submerged in water and quantitative eclosion evaluated for the next 10 days (Luz et al. 2007). Four independent replicates, each test using different fungal cultures, were carried out. Rates of eclosion were arcsine-square root transformed and evaluated by analyses of variance and the Student-Newman-Keuls multiple range test for comparison of means. Means were considered not statistically different at $\mathrm{p}>0.05$.

At only the highest ( $>98 \%) \mathrm{RH}$, mycelium and newly formed conidia of $M$. anisopliae were observed by the end of the first month of incubation. Control eggs held at the same humidity were found to be infested with saprobic fungi. There was a clear effect of moisture on cumulative eclosion of larvae 10 days after immersion of eggs in water regardless of the treatment $\left(\mathrm{F}_{3,28}=23.2\right.$; $\mathrm{p}<0.001)$. Eclosion was $\geq 80 \%$ after one month of exposure of eggs at $43-86 \% \mathrm{RH}$, but dropped to $\leq 1.3 \%$ at $43 \% \mathrm{RH}$, to $\leq 27.5 \%$ at $75 \% \mathrm{RH}$ and to $\leq 20 \%$ at $86 \%$ RH, six months after treatment for both fungus- and 
water-treated eggs (Figure). At $>98 \%$ RH eclosion differed clearly between fungus-treated and control eggs after the first month, with greater eclosion values for the controls than for fungus-treated eggs. Whereas eclosion of fungus-treated eggs incubated at $>98 \% \mathrm{RH}$ for six months did not exceed $1.3 \%$, eclosion in the control (water-treated) eggs reached up to $26.3 \%$ at the same time (Figure). No difference of quantitative eclosion was found between eggs treated with conidia or hyphal bodies. These results confirmed that moisture is a limiting
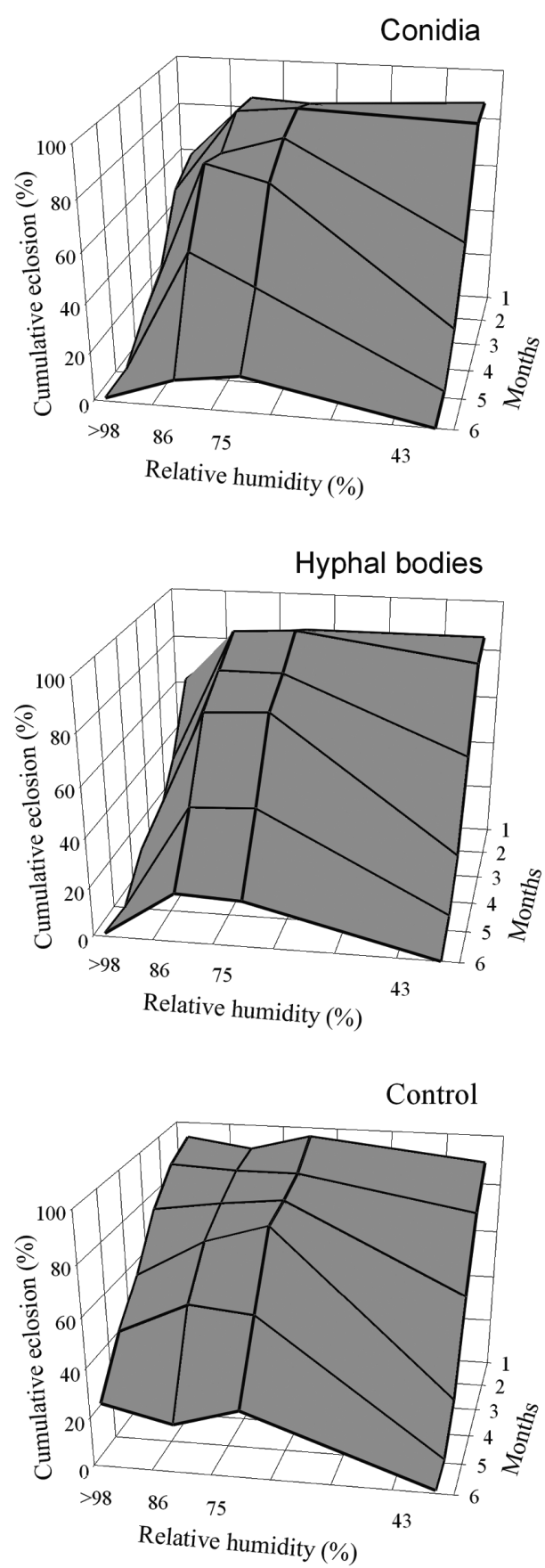

Cumulative eclosion of Aedes aegypti eggs treated with Metarhizium anisopliae IP 46 or water and exposure at different humidities and $25^{\circ} \mathrm{C}$ up to six months before submersion in water for 10 days. factor for the survival of $A$. aegypti eggs, and that larvae inside eggs survived better at higher moisture levels. $M$. anisopliae had a strong ovicidal effect only at RH close to saturation. A high potential for biological control of A. aegypti can be expected during the rainy season and throughout the year in either subterranean breeding sites, man-made containers or plants with accumulated water where humidity is constantly high and where female mosquitoes preferentially oviposit.

\section{ACKNOWLEDGEMENTS}

To Carmeci N. Elias for rearing the mosquitoes and Richard A. Humber for the critical review of the manuscript.

\section{REFERENCES}

Goettel MS, Inglis GD 1997. Fungi: Hyphomycetes. In Manual of Techniques in Insect Pathology. L Lawrence, Academic Press, New York, p. 213-250.

Luz C, Tai MHH, Santos AH, Rocha LFN, Albernaz DAS, Silva HHG 2007. Ovicidal activity of entomopathogenic Hyphomycetes on Aedes aegypti (L.) (Diptera: Culicidae) under laboratory conditions. J Med Entomol 44: 799-804.

Maciel-de-Freitas R, Marques WA, Peres RC, Cunha SP, Lourençode-Oliveira R 2007. Variation in Aedes aegypti (Diptera: Culicidae) container productivity in a slum and a suburban district of Rio de Janeiro during dry and wet seasons. Mem Inst Oswaldo Cruz 102: 489-496.

Russell BM, Kay BH, Shipton W 2001. Survival of Aedes aegypti (Diptera: Culicidae) eggs in surface and subterranean breeding sites during the Northern Queensland dry season. J Med Entomol 38: 441-445.

Scholte EJ, Knols BGJ, Samson RA, Takken W 2004. Entomopathogenic fungi for mosquito control: a review. J Insect Sci 4: 19.

Scholte EJ, Takken W, Knols BGJ 2007. Infection of adult Aedes aegypti and Ae. albopictus mosquitoes with the entomopathogenic fungus Metarhizium anisopliae. Acta Trop 102: 151-158.

Silva HHG, Silva IG, Lira KS 1998. Metodologia de criação, manutenção de adultos e estocagem de ovos de Aedes aegypti (Linnaeus, 1762) em laboratório. Rev Patol Trop 27: 53-63.

Silva HHG, Silva IG 1999. Influência do período de quiescência dos ovos sobre o ciclo de vida de Aedes aegypti (Linnaeus, 1762) (Dipera, Culicidae) em condições de laboratório. Rev Soc Bras Med Trop 32: 349-355.

Silva RO, Silva HHG, Luz C 2004. Effect of Metarhizium anisopliae isolated from soil samples of the central Brazilian cerrado against Aedes aegypti larvae under laboratory conditions. Rev Pat Trop 33: 207-216.

Silva RO, Silva HHG, Ulhoa CJ, Luz C 2005. Is there a relationship between $\mathrm{N}$-acetyl-beta-D-glucosaminidase activity of Metarhizium anisopliae (Metschn.) Sorokin (Hyphomycetes) isolates from peridomestic areas in Central Brazil and larvicidal effect on Aedes aegypti (L.) (Diptera, Culicidae)? J Appl Entomol 129: 158-164.

Sota T, Mogi M 1992. Survival time and resistance to desiccation of diapause and non-diapause eggs of temperate Aedes (Stegomyia) mosquitoes. Entomol Exp Appl 63: 155-161.

Varejão JBM, Santos CB, Rezende HR, Bevilacqua LC, Falqueto A 2005. Criadouros de Aedes (Stegomyia) aegypti (Linnaeus 1762) em bromélias nativas na cidade de Vitória, ES. Rev Soc Bras Med Trop 38: 238-240.

Winston PW, Bates DH 1960. Saturated solutions for the control of humidity in biological research. Ecology 41: 232-237. 